\title{
Mapping of Kobresia pygmaea Community Based on Umanned Aerial Vehicle Technology and Gaofen Remote Sensing Data in Alpine Meadow Grassland: A Case Study in Eastern of Qinghai-Tibetan Plateau
}

\author{
Baoping Meng ${ }^{1,2} \mathbb{D}^{\mathbb{D}}$, Zhigui Yang ${ }^{1,2} \mathbb{D}$, Hongyan $\mathrm{Yu}^{3}$, Yu Qin ${ }^{4}$, Yi Sun ${ }^{1,2}$, Jianguo Zhang ${ }^{1,2}$, Jianjun Chen ${ }^{5} \mathbb{D}$, \\ Zhiwei Wang ${ }^{6}\left(\mathbb{D}\right.$, Wei Zhang ${ }^{4}$, Meng $\mathrm{Li}^{1,2}$, Yanyan Lv ${ }^{1,2}$ and Shuhua $\mathrm{Yi}^{1,2, * \mathbb{D}}$ \\ 1 Institute of Fragile Eco-Environment, Nantong University, Nantong 226007, China; \\ mengbp09@lzu.edu.cn (B.M.); 1822021025@stmail.ntu.edu.cn (Z.Y.); sunyi@ntu.edu.cn (Y.S.); \\ sezjg@ntu.edu.cn (J.Z.); limeng@ntu.edu.cn (M.L.); lvyy09@lzu.edu.cn (Y.L.) \\ 2 School of Geographic Science, Nantong University, Nantong 226007, China \\ 3 Qinghai Service and Guarantee Center of Qilian Mountain National Park, Xining 810001, China; \\ 18909718038@189.cn \\ 4 State Key Laboratory of Cryospheric Sciences, Northwest Institute of Eco-Environment and Resources, \\ Chinese Academy of Sciences, 320 Donggang West Road, Lanzhou 730000, China; qiny@lzb.ac.cn (Y.Q.); \\ zhangwei2015@1zb.ac.cn (W.Z.) \\ check for \\ updates \\ Citation: Meng, B.; Yang, Z.; Yu, H.; \\ Qin, Y.; Sun, Y.; Zhang, J.; Chen, J.; \\ 5 College of Geomatics and Geoinformation, Guilin University of Technology, 12 Jiangan Road, \\ Guilin 541004, China; chenjj@lzb.ac.cn \\ 6 Guizhou Institute of Prataculture, Guizhou Academy of Agricultural Sciences, Guiyang 550006, China; \\ wzw1206@lzb.ac.cn \\ * Correspondence: yis@ntu.edu.cn
} Wang, Z.; Zhang, W.; Li, M.; et al. Mapping of Kobresia pygmaea Community Based on Umanned Aerial Vehicle Technology and Gaofen Remote Sensing Data in Alpine Meadow Grassland: A Case Study in Eastern of Qinghai-Tibetan Plateau. Remote Sens. 2021, 13, 2483. https://doi.org/10.3390/rs13132483

Academic Editor: Elias Symeonakis

Received: 21 May 2021

Accepted: 22 June 2021

Published: 25 June 2021

Publisher's Note: MDPI stays neutral with regard to jurisdictional claims in published maps and institutional affiliations.

Copyright: (c) 2021 by the authors. Licensee MDPI, Basel, Switzerland. This article is an open access article distributed under the terms and conditions of the Creative Commons Attribution (CC BY) license (https:// creativecommons.org/licenses/by/ $4.0 /)$.

\begin{abstract}
The Kobresia pygmaea (KP) community is a key succession stage of alpine meadow degradation on the Qinghai-Tibet Plateau (QTP). However, most of the grassland classification and mapping studies have been performed at the grassland type level. The spatial distribution and impact factors of KP on the QTP are still unclear. In this study, field measurements of the grassland vegetation community in the eastern part of the QTP (Counties of Zeku, Henan and Maqu) from 2015 to 2019 were acquired using unmanned aerial vehicle (UAV) technology. The machine learning algorithms for grassland vegetation community classification were constructed by combining Gaofen satellite images and topographic indices. Then, the spatial distribution of KP community was mapped. The results showed that: (1) For all field observed sites, the alpine meadow vegetation communities demonstrated a considerable spatial heterogeneity. The traditional classification methods can hardly distinguish those communities due to the high similarity of their spectral characteristics. (2) The random forest method based on the combination of satellite vegetation indices, texture feature and topographic indices exhibited the best performance in three counties, with overall accuracy and Kappa coefficient ranged from $74.06 \%$ to $83.92 \%$ and 0.65 to 0.80 , respectively. (3) As a whole, the area of KP community reached $1434.07 \mathrm{~km}^{2}$, and accounted for $7.20 \%$ of the study area. We concluded that the combination of satellite remote sensing, UAV surveying and machine learning can be used for KP classification and mapping at community level.
\end{abstract}

Keywords: Kobresia pygmaea community; unmanned aerial vehicle; Gaofen satellite; spatial distribution

\section{Introduction}

Alpine meadow is the major vegetation type on the Qinghai-Tibet Plateau (QTP), China. It is important for animal husbandry, water conservation and biodiversity conservation [1,2]. Since the 1980s, due to the dual effects of climate change and human activities, alpine meadow grassland has experienced different extents of degradation, especially in 
the source region of Yellow River, which is on the eastern part of the QTP [3]. The degradation has restricted the sustainable development of animal husbandry and seriously threatened local ecological security [4]. The degradation succession stages of the alpine meadow grassland community include Poaceae, Kobresia humilis $(\mathrm{KH})$, Kobresia pygmaea (KP) and black soil type (BS). The KP community is the key stage for the management of degraded grassland [5]. In the first two stages, the original community structure and function can be quickly restored under the grazing prohibition and artificial measures [6]. However, further degradation of KP community will cause irreversible degradation until the severest stage of black soil type [7]. Therefore, it is vital to map the current distribution of KP community grassland for mitigation and adaptation measures. However, previous grassland classifications have been performed at the vegetation type level, and few at the community level $[8,9]$. At present, the spatial distribution and impact factors of KP community on the QTP are still unclear $[1,2,10]$. Therefore, it is urgent to develop a method for mapping alpine meadow at community level.

Traditional grassland vegetation community samples are mainly obtained with the few field investigation, expert knowledge and literature reviews. Due to the complex distribution and dynamic of grassland vegetation communities, the field investigation cannot meet the accuracy requirement of classification [11-15]. In addition, remote sensing (RS) vegetation indices have been commonly used as classification variables, "the same object with different spectrum" or "the different object with same spectrum" have occurred frequently [16-18]. Successful classifications at the community level requires: (1) the RS images with proper temporal-spatial resolution, coverage, sensitive spectrum band; (2) massive field observations; and (3) effective classification methods.

Compared with traditional multi-spectral remote sensing (e.g., MODIS, Landsat, HJ1A/1B), the Gao Fen 1 (GF1) and Gao Fen 6 (GF6) satellites have significant advantages in grassland resource monitoring [19]. Each of these satellites has a high resolution of $16 \mathrm{~m}$ (wide field view images, WFV), a relatively large detection width of $800 \mathrm{~km}$ and a short revisit period of two days (four days for each, two days for combination) [20]. Additionally, GF6 satellite adds the red edge band, which is beneficial to vegetation classification. Thus, it is easier to collect high quality remote sensing images at a regional scale [21].

The massive field observation is the basis of RS classification of grassland communities. However, the resolution of satellite images is insufficient to identify grassland communities, and traditional methods require large amounts of time, labor, cost and resources. In recent years, with the development of unmanned aerial vehicle (UAV) technology, the shortcoming of satellite and traditional methods in grassland resource monitoring are supplied [22-24]. On the one hand, the aerial photographs provided by UAV have high resolution, which can be used to identify the grassland vegetation community effectively [25]. On the other hand, UAV has a large observation range, which can save time and effort. Yi et al. (2017) [26] also developed a set of UAV aerial photography system with fixed-point, multi-site, collaborative observation, which can realize massive observation over large regions [27].

With the development of classification methods, machine learning algorithm has obvious advantages in RS image classification [28,29]. Based on neural network (NN), support vector machine (SVM), random forest (RF) and other machine learning algorithms, the satellite vegetation index, phrenological characteristics, image texture and topography are considered to improve the accuracy of RS classification [24,30-32]. However, RS classification in grassland mainly includes the land use type (e.g., grassland, non-grassland, woodland, etc.) [33], different biophysics characteristics (such as grassland with high, medium and low coverage) [34] and types in different climatic zones (such as class, group and type of grassland) [35].

In this study, we aimed to map the KP community over the eastern of QTP by using the combination of UAV aerial photographing, GF WFV images and machine learning algorithms. We hope this study can be helpful for guiding further mapping of the KP 
community over the whole QTP and provide scientific basics for restoration and management activities.

\section{Data and Methods}

\subsection{Study Area}

The study area is located at the eastern of the source region of the Yellow River, including Zeku County and Henan County of Qinghai province, and Maqu County of Gansu province (Figure 1). It is one of the most important animal husbandry basis on the QTP and also an important water source conservation area in China. The study area is located at $33^{\circ} 03^{\prime} \sim 35^{\circ} 33^{\prime} \mathrm{N}, 100^{\circ} 33^{\prime} \sim 102^{\circ} 33^{\prime} \mathrm{E}$, with elevation ranging from 2871 to $4850 \mathrm{~m}$ (Figure 1c). The mean annual precipitation ranges from $400 \sim 600 \mathrm{~mm}$, mean annual temperature is between $-2.4 \sim 2.1^{\circ} \mathrm{C}$ It belongs to the continental plateau temperate monsoon climate. Alpine meadow is one of the main alpine grassland types, accounting for $79.67 \%$ of the whole study area. Other than alpine meadow, mountain meadow, swamp meadow and alpine steppe account for $13.22 \%, 1.78 \%$, and 1.69\%, respectively (Figure $1 \mathrm{~b}$ ). The growth period of grassland plants is relatively short, only about 150 days, mainly from May to September. The grasslands are mainly used for yak and sheep grazing.
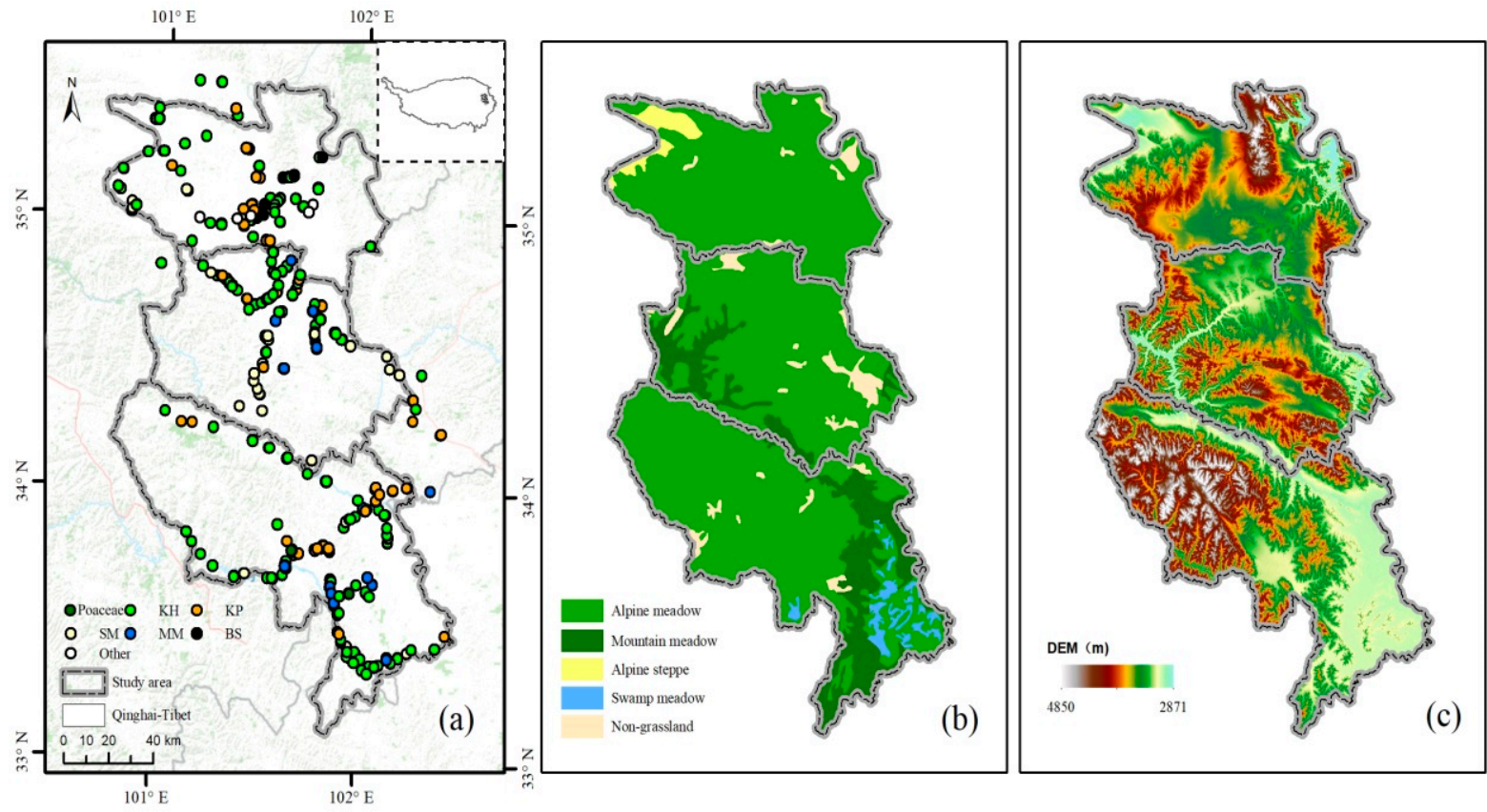

Figure 1. Location, grassland type and topography of study area. (a) Location of the study area in Qinghai-Tibetan Plateau and the observation sites; dots of different color represent the vegetation communities. Poaceae: Elymus nutans + Stipa silena + Festuca ovina community, KH: Kobresia humilis community, KP: Kobresia pygmaea community, BS: black soil type, MM: marsh meadow, SM: shrub meadow. (b) Grassland type of study area; (c) topography of study area.

\subsection{Data and Preprocessing}

\subsubsection{Field Observation and Preprocess of Aerial Photographs}

We carried out the field monitoring for vegetation communities of alpine meadow based on aerial photographs by Phantom 3 professional and Mavic 2 zoom Quad-Rotor intelligent UAVs (manufactured by DJI Innovation Industries; http:/ / www.dji.com (accessed on 1 June 2018). According to grassland growth status and spatial representativeness, an area in the range of $250 \times 250 \mathrm{~m}$ was selected as an observation site, and four flight routes were designed in each site, including one GRID flight way $(200 \times 200 \mathrm{~m})$ and three BELT flight ways $(40 \times 40 \mathrm{~m})$ (Figure 2a). The flight way of UAVs was designed by FragMAP [22], Phantom 3 professional was used to perform the GRID flight way at a height of $20 \mathrm{~m}$ (red dot in Figure 2a,b), Mavic 2 zoom was used to perform the BELT flight way at a height 
of $2 \mathrm{~m}$ (green dot in Figure 2a,c). The positional accuracy of two UAVs was $\pm 1.5 \mathrm{~m}$ horizontally and $\pm 0.5 \mathrm{~m}$ vertically. A photograph was then taken vertically downward at each way point automatically, the photograph resolutions of GRID and BELT were 1 and $0.09 \mathrm{~cm}$, and the ground coverages were $26 \times 35 \mathrm{~m}$ and $2.57 \times 3.43 \mathrm{~m}$, respectively.
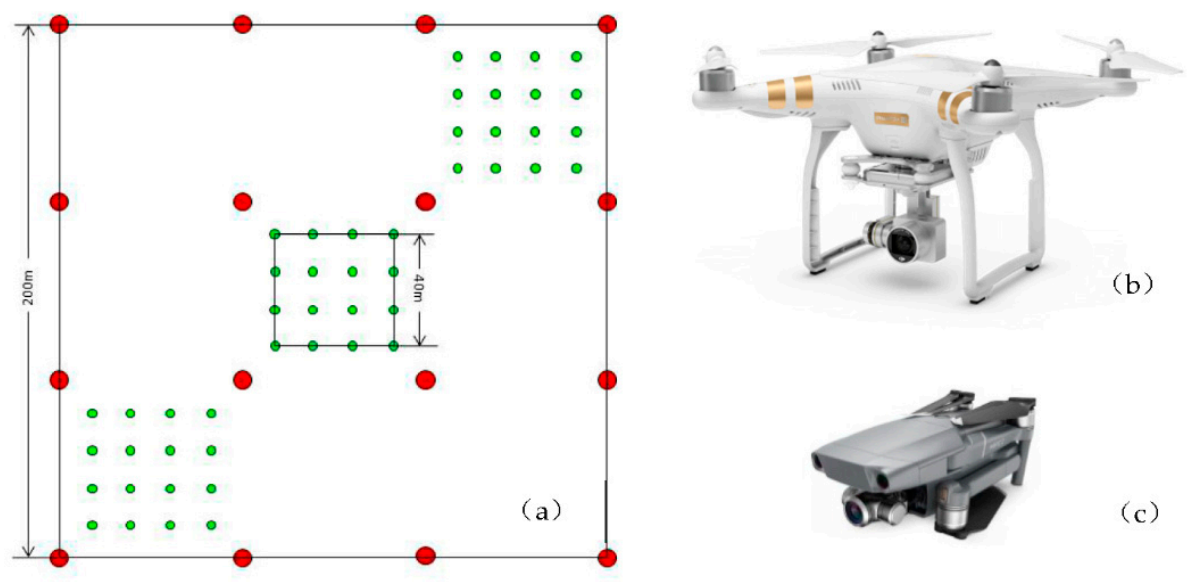

Figure 2. Strategy of field observation and data collection: (a) strategy of observation site; (b) Phantom 3 professional and (c) Mavic 2 zoom Quad-Rotor intelligent UAVs.

To better identify the vegetation species, about 9 15 aerial photographs were collected randomly by operating Mavic 2 zoom manually at a height of $0.5 \mathrm{~m}$ in each sample site. The number of photographs was determined by the uniformity of community growth status. These aerial photographs could clearly identify plant species, which was corresponding to the traditional ground observation quadrat (Supplementary Figure S1).

According to the dominant species of grass vegetation, grassland coverage, texture features and plateau pika (Ochotona curzoniae, hereafter pika) activities, the aerial photographs were divided into six types, including four alpine meadow vegetation communities of Poaceae, KH, KP and BS (Figure 3 and Table 1), two land covers of shrub meadow (SM) and marsh meadow (MM). Additionally, the forest and others (bare land, construction use and waters) were acquired based on the Google Earth images and GF WFV images. Field observation was carried out at the peak time of grassland growth, and 751 sample sites were observed from 2015 to 2019 in total (Figure 1c). About 30 sample sites were acquired for forest and others.

\subsubsection{Region of Interest Construction}

According to the GPS information recorded in FragMAP and stored in aerial photographs property files, the names of photographs were renamed by the number of 1 to 16 by the DJI Locator software [22] in each site. Then the region of interest was built based on photograph location information in the same observation site in ArcGIS and ENVI software (Figure 3d,h,l,p). Additionally, about 30 samples (region of interest, ROI) for forest and others (the water, bare land, and construction land) were selected in ENVI software, according to the GF WFV images and Google Earth images. 


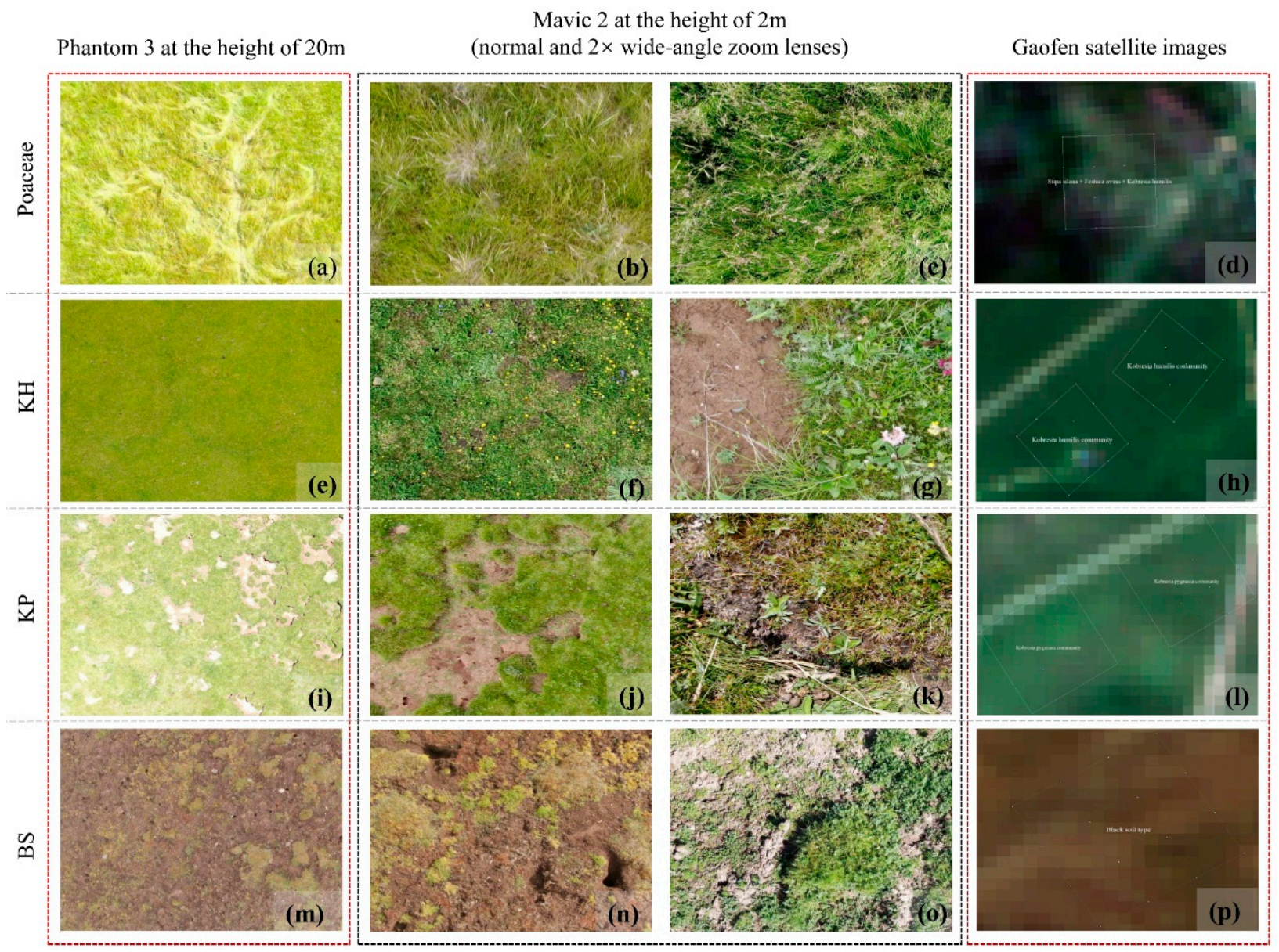

Figure 3. Classification criteria for aerial photographs of alpine meadow vegetation communities. (a,e,i,m) were aerial photographs taken at the height of $20 \mathrm{~m}$ by Phantom 3. (b, $\mathbf{c}, \mathbf{f}, \mathbf{g}, \mathbf{j}, \mathbf{k}, \mathbf{k}, \mathbf{n}, \mathbf{o})$ were aerial photographs taken at a height of $2 \mathrm{~m}$ by Mavic 2 . (c, $\mathbf{g}, \mathbf{k}, \mathbf{o})$ acquired with $2 \times$ wide-angle zoom lenses; $(\mathbf{d}, \mathbf{h}, \mathbf{l}, \mathbf{p})$ were Gaofen images of four types of vegetation communities corresponded; Poaceae, KH, KP and BS represented communities of Elymus nutans + Stipa silena + Festuca ovina, Kobresia humilis, Kobresia pygmaea and black soil type, respectively.

Table 1. Characteristics of vegetation communities in alpine meadow.

\begin{tabular}{|c|c|c|c|}
\hline Community & Dominant Species & Coverage & Other Features \\
\hline Poaceae & $\begin{array}{c}\text { Elymus nutans, Stipa silena, } \\
\text { Festuca ovina }\end{array}$ & More than $90 \%$ & $\begin{array}{c}\text { Tall grassland height (20-50 cm in height), } \\
\text { grassland was flat without any traces of } \\
\text { pika activity }\end{array}$ \\
\hline $\mathrm{KH}$ & $\begin{array}{c}\text { Kobresia humilis; } \\
\text { sub-dominant: Elymus nutans } \\
\text { and Festuca rubra }\end{array}$ & More than $90 \%$ & $\begin{array}{c}\text { Grassland was flat with low height }(<10 \mathrm{~cm} \\
\text { in height) and high coverage, and small } \\
\text { number of pika appeared }\end{array}$ \\
\hline $\mathrm{KP}$ & Kobresia pygmaea & Between 30 80\% & $\begin{array}{l}\text { Grassland had a unique morphology and } \\
\text { textural characteristics, with closed and } \\
\text { monospecific builds }(2 \sim 3 \mathrm{~cm} \text { in height), } \\
\text { polygonal crack patterns and a felty root } \\
\text { mat, pika and poisonous weeds are } \\
\text { invaded frequently }\end{array}$ \\
\hline BS & Weeds & Less than $20 \%$ & $\begin{array}{c}\text { Pika was rampant and weeds } \\
\text { was overgrown }\end{array}$ \\
\hline
\end{tabular}

Poaceae, KH, KP and BS represented Elymus nutans + Stipa silena + Festuca ovina, Kobresia humilis, Kobresia pygmaea and black soil type, respectively. 


\subsubsection{Acquisition and Preprocessing of Remote Sensing Data}

The remote sensing data, including GF1 and GF6 WFV imager images, were downloaded from the China Centre for Resources Satellite Data and Application (http:/ / www. cresda.com/EN/ (accessed on 20 September 2019)). The WFV imager was carried by GF1 and GF2 satellites, with four multi-spectral bands ( $800 \mathrm{~km}$ of swath width) and eight multi-spectral bands ( $850 \mathrm{~km}$ of swath width), respectively. The resolution of WFV image was $16 \mathrm{~m}$, and the revisit period for each satellite was 4 days. Together, the revisit period could be reached up to 2 days (Table 2). Three scenes of WFV images with no cloud cover in Zeku, Henan and Maqu, during the peak of grassland growth of 2019 and 2020 were downloaded (Table 3). The GF WFV data were preprocessed using ENVI 5.3 software, and the Radiometric Calibration module, FLAASH Atmospheric Correction module and RPC (Rational Polynomial Coefficient) Orthorectification module was used for converting the original DN value to atmospheric surface reflectance, atmospheric correction and precise geometric correction of WFV images, respectively. Then, the Band Math module was used to calculate the vegetation indices of NDVI, NDWI and NDMI. The Co-occurrence measures module was used to extract image texture features of WFV images based on a sliding window with $3 \times 3$ pixels, and the texture indices mainly included Mean, Variance, Homogeneity, Contrast, Dissimilarity, Entropy, Second Moment and Correlation.

Table 2. characterization of Gao Fen (GF) wide field view (WFV) cameras.

\begin{tabular}{|c|c|c|c|c|c|c|c|}
\hline Satellite & Band & $\begin{array}{c}\text { Spectral } \\
\text { Range }(\mu \mathrm{m})\end{array}$ & Band Type & $\begin{array}{c}\text { Spatial } \\
\text { Resolution (m) }\end{array}$ & $\begin{array}{c}\text { Swath } \\
\text { Width (km) }\end{array}$ & $\begin{array}{c}\text { Revisit } \\
\text { Period (day) }\end{array}$ & $\begin{array}{l}\text { Orbit Altitude } \\
(\mathbf{k m})\end{array}$ \\
\hline \multirow{4}{*}{ GF-1 } & 1 & $0.45-0.52$ & Blue & \multirow{4}{*}{16} & \multirow{4}{*}{800} & \multirow{4}{*}{4} & \multirow{4}{*}{675} \\
\hline & 2 & $0.52-0.59$ & Green & & & & \\
\hline & 3 & $0.63-0.69$ & Red & & & & \\
\hline & 4 & $0.77-0.89$ & NIR & & & & \\
\hline \multirow{8}{*}{ GF-6 } & 1 & $0.45-0.52$ & Blue & \multirow{8}{*}{16} & \multirow{8}{*}{800} & \multirow{8}{*}{4} & \multirow{8}{*}{645} \\
\hline & 2 & $0.52-0.59$ & Green & & & & \\
\hline & 3 & $0.63-0.69$ & Red & & & & \\
\hline & 4 & $0.77-0.89$ & NIR & & & & \\
\hline & 5 & $0.69-0.73$ & Red edge 1 & & & & \\
\hline & 6 & $0.73-0.77$ & Red edge 2 & & & & \\
\hline & 7 & $0.40-0.45$ & Purple & & & & \\
\hline & 8 & $0.59-0.63$ & Yellow & & & & \\
\hline
\end{tabular}

Table 3. List of GF1/6 WFV images used in this study.

\begin{tabular}{cccccc}
\hline County & $\begin{array}{c}\text { Data of Satellite } \\
\text { Images }\end{array}$ & Satellite & Path & Row & $\begin{array}{c}\text { Central Latitude } \\
\text { and Longitude }\end{array}$ \\
\hline Zeku & 2019.06 .03 & GF1 & 23 & 98 & E 101.9, N 34.7 \\
Henan & 2019.08 .15 & GF6 & 30 & 72 & E 98.1, N 35.8 \\
Maqu & 2020.08 .25 & GF6 & 18 & 72 & E 104.7, N33.6 \\
\hline
\end{tabular}

The DEM data were $90 \mathrm{~m}$ shuttle radar topography mission (SRTM) images (version V004) (http:/ / srtm.csi.cgiar.org/ (accessed on 1 June 2018) in Geo-TIFF format. The Slope, topographic position index (TPI) and aspect were calculated based on the DEM. Then, all indices above mentioned were uniformly projected as UTM_Zone_47N (same as GF WFV). 


\subsection{Vegetation Community Classification and Accuracy Evaluation}

\subsubsection{Classification Method}

The maximum likelihood estimate (MLE), NN, SVM and RF classification methods were employed. MLE assuming each statistic of different types in every band was normally distributed, the likelihood of each pixel belonging to a certain training sample was calculated. Finally, the type of pixel was determined based on the highest likelihood [36]. NN (also called artificial neural network, ANN) referred to a multi-layer network structure, the Levenberg-Marquardt function algorithm was selected for NN training. The number of neurons and hidden layers were determined based on a trial-and-error process [37]. SVM was constructed by a set of hyperplanes in high- or infinite-dimensional space, the higher the functional margin, the lower the generalization error of the classifier. The radial basis function (RBF) was used as the kernel function, and the optimal cost and gamma values were obtained for final classification [38,39]. The RF algorithm was constructed by the classification tree, which applied a set of decision trees to improve prediction accuracy. The bootstrap sample was employed to construct a decision tree. The training samples were constantly selected to minimize the sum of the squared residuals until a complete tree was formed. Multiple decision trees were formed, and voting was used to obtain the final prediction [40,41]. MLE, NN and SVM methods were performed in ENVI supervised classification toolboxes of Maximum Likelihood Classification, Neural Net Classification and Support Vector Machine Classification, respectively. RF method was performed in ENVI Extensions toolbox of Random Forest Classification [42].

\subsubsection{Classification and Accuracy Evaluation}

Given the classification accuracy and efficiency, three input datasets were used: (1) GF1/6 WFV spectral band (band1 to band8); (2) vegetation and texture indices (NDVI, NDWI, SAVI, Contrast, Correlation, Dissimilarity, Entropy, Homogeneity, Mean, Second moment and Variance); (3) vegetation, texture, and topography indices (DEM, Slope, Asp and TPI). About $70 \%$ of observation sites were selected randomly as a training set, and the rest were used to validate classification accuracy in each county. The standard confusion matrix was employed to evaluate the classification accuracy of images, and the overall accuracy (OA), Kappa coefficient (Kappa), user's accuracy (UA) and producer' accuracy (PA) based on the validation datasets were used to assess the precision of classification results.

\section{Results}

\subsection{Characteristics of Field Observation and Its Corresponding Multi-Indices}

The distribution of observed sites was shown in Figure 1a. The vegetation communities of alpine meadow showed a considerable spatial heterogeneity. Among the 751 observed sites, the proportion of $\mathrm{KH}$ community is highest, with $56.32 \%$ of all observed sites. Followed by KP community (17.04\% of all observed sites), the number of KP community observation sites were 68, 37 and 22 for Maqu, Zeku and Henan, respectively. The proportion of SM, MM, BS and Poaceae only accounted for 3.33 9.85\% of all observed sites.

For the four types of alpine meadow grass communities and four types of land cover, the statistics of GF1/GF6 WFV image bands, vegetation indices, topography indices and texture indices were calculated in the study area (in Supplementary Materials). The result showed that the characteristics of multi-indices in alpine meadow vegetation communities were very similar, and it was difficult to distinguish with commonly used indices (Figure $4 \mathrm{a}, \mathrm{b}, \mathrm{e})$. Even though eight land covers could be coarsely distinguished between each other in red edge bands (band5 and band6 of WFV image) and DEM, there was relatively large error in classification (with little difference in mean values and wide range in variation) (Figure $4 \mathrm{c}, \mathrm{d}, \mathrm{f})$. 

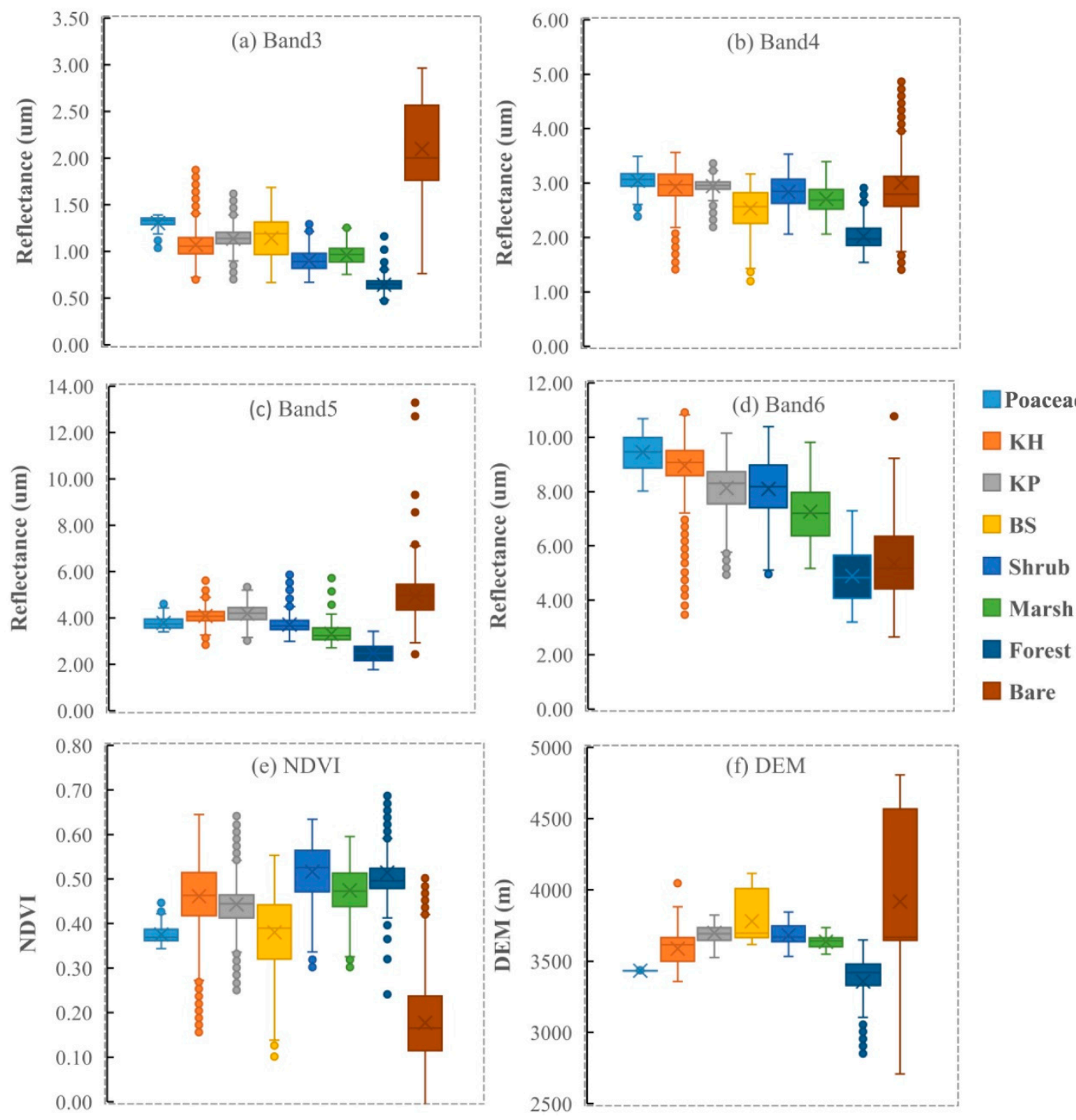

Figure 4. Statistical analysis results of band3 to band6 of GF1/GF6 images (a-d), NDVI (e) and DEM (f), respectively; Poaceae, KH, KP and BS represent Elymus nutans + Stipa silena + Festuca ovina, Kobresia humilis, Kobresia pygmaea and black soil type, respectively.

\subsection{Accuracy Evaluation of the Different Classification Methods}

Accuracy assessment of classification was performed with the validation samples listed in Table 4. Among the four classification methods, the RF method performed best, with the highest overall accuracy and Kappa coefficient ranged from $74.06 \%$ to $83.92 \%$ and from 0.65 to 0.80 in three counties, respectively. This was followed by the SVM method, with an overall accuracy that ranged from $69.39 \%$ to $78.53 \%$ and Kappa coefficient that ranged from 0.60 to 0.73 . The accuracies of the NN and MLE method were the worst (overall accuracy ranged from $40.78 \%$ to $73.89 \%$; Kappa coefficient ranged from 0.24 to 0.67). Among the three classifications input, in general, the MLE, SVM and RF methods based on the input data set of vegetation indices + texture + topography exhibited the best performance, followed by the spectrum and vegetation indices + texture. However, the performance of the NN method based on the above input data set showed contrary results to the MLE, SVM and RF methods. 
Table 4. Overall accuracy and Kappa coefficient of eight land covers based on maximum likelihood estimate (MLE), neural network (NN), support vector machine (SVM) and random forest (RF) and difference input data set in County of Zeku, Henan and Maqu.

\begin{tabular}{|c|c|c|c|c|c|c|}
\hline \multirow{2}{*}{ County } & \multirow{2}{*}{ Input } & \multirow{2}{*}{ Accuracy } & \multicolumn{4}{|c|}{ Methods } \\
\hline & & & MLE & NN & SVM & RF \\
\hline \multirow{6}{*}{ Zeku } & \multirow{2}{*}{ Spectrum } & OA (\%) & 57.36 & 71.22 & 72.13 & 82.24 \\
\hline & & Kappa & 0.50 & 0.64 & 0.65 & 0.78 \\
\hline & \multirow{2}{*}{ Vegetation indices + texture } & OA (\%) & - & 63.36 & 69.39 & 79.87 \\
\hline & & Kappa & - & 0.52 & 0.61 & 0.75 \\
\hline & \multirow{2}{*}{ Vegetation indices + texture + topography } & $\mathrm{OA}(\%)$ & 63.75 & 40.78 & 78.53 & 83.92 \\
\hline & & Kappa & 0.57 & 0.24 & 0.73 & 0.80 \\
\hline \multirow{6}{*}{ Henan } & \multirow{2}{*}{ Spectrum } & OA (\%) & 68.03 & 75.14 & 74.96 & 81.32 \\
\hline & & Kappa & 0.60 & 0.67 & 0.66 & 0.76 \\
\hline & \multirow{2}{*}{ Vegetation indices + texture } & OA (\%) & 72.04 & 65.89 & 73.31 & 80.39 \\
\hline & & Kappa & 0.64 & 0.54 & 0.65 & 0.75 \\
\hline & \multirow{2}{*}{ Vegetation indices + texture + topography } & OA (\%) & 73.89 & 49.86 & 73.89 & 78.86 \\
\hline & & Kappa & 0.66 & 0.34 & 0.66 & 0.73 \\
\hline \multirow{6}{*}{ Maqu } & \multirow{2}{*}{ Spectrum } & OA (\%) & 65.67 & 70.04 & 70.28 & 75.96 \\
\hline & & Kappa & 0.56 & 0.60 & 0.60 & 0.68 \\
\hline & \multirow{2}{*}{ Vegetation indices + texture } & OA (\%) & 51.38 & 67.12 & 73.78 & 74.06 \\
\hline & & Kappa & 0.40 & 0.55 & 0.65 & 0.65 \\
\hline & \multirow{2}{*}{ Vegetation indices + texture + topography } & OA (\%) & 65.19 & 61.89 & 74.09 & 82.75 \\
\hline & & Kappa & 0.56 & 0.46 & 0.65 & 0.77 \\
\hline
\end{tabular}

Note: overall accuracy, OA; maximum likelihood estimate, MLE; neural network, NN; support vector machine, SVM; random forest, RF.

The results of the standard confusion matrix were shown in Table 5. The PA and UA based on the RF method were highest in three counties, with $60.84 \%$ to $97.23 \%$ and $60.73 \%$ to $78.09 \%$, respectively. The PA and UA based on other methods showed lower value, and the classification results of the KP community were easily confused with other grass communities and land cover types.

Table 5. Producer's accuracy and user's accuracy of Kobresia pygmaea community based on maximum likelihood estimate (MLE), neural network (NN), support vector machine (SVM) and random forest (RF) in Zeku, Henan and Maqu County.

\begin{tabular}{|c|c|c|c|c|c|c|}
\hline \multirow{2}{*}{ County } & \multirow{2}{*}{ Input } & \multirow{2}{*}{ Accuracy (\%) } & \multicolumn{4}{|c|}{ Method } \\
\hline & & & MLE & $\mathbf{N N}$ & SVM & RF \\
\hline \multirow{6}{*}{ Zeku } & \multirow{2}{*}{ Spectrum } & PA & 50.99 & 26.06 & 39.83 & 96.37 \\
\hline & & UA & 49.01 & 47.96 & 56.89 & 74.07 \\
\hline & \multirow{2}{*}{ Vegetation indices + texture } & PA & - & 38.83 & 19.61 & 86.94 \\
\hline & & UA & - & 46.85 & 46.49 & 69.94 \\
\hline & \multirow{2}{*}{ Vegetation indices + texture + topography } & PA & 69.30 & 64.93 & 84.82 & 97.23 \\
\hline & & UA & 46.45 & 43.34 & 57.38 & 65.68 \\
\hline \multirow{6}{*}{ Henan } & \multirow{2}{*}{ Spectrum } & PA & 59.61 & 5.71 & 5.26 & 67.57 \\
\hline & & UA & 29.83 & 80.85 & 57.38 & 60.81 \\
\hline & \multirow{2}{*}{ Vegetation indices +texture } & PA & 26.58 & 10.06 & 26.88 & 76.73 \\
\hline & & UA & 41.75 & 44.97 & 54.43 & 67.59 \\
\hline & \multirow{2}{*}{ Vegetation indices + texture + topography } & PA & 35.83 & - & 32.83 & 68.67 \\
\hline & & UA & 41.86 & - & 46.40 & 67.65 \\
\hline \multirow{6}{*}{ Maqu } & \multirow{2}{*}{ Spectrum } & PA & 70.68 & 64.83 & 52.74 & 67.23 \\
\hline & & UA & 43.68 & 49.41 & 50.67 & 59.29 \\
\hline & \multirow{2}{*}{ Vegetation indices + texture } & PA & 59.45 & 13.68 & 61.32 & 60.84 \\
\hline & & UA & 50.00 & 90.48 & 61.21 & 60.73 \\
\hline & \multirow{2}{*}{ Vegetation indices + texture + topography } & PA & 70.48 & 35.83 & 64.22 & 73.96 \\
\hline & & UA & 45.53 & 52.32 & 57.42 & 78.09 \\
\hline
\end{tabular}

Note: producer's accuracy, PA; user's accuracy, UA; maximum likelihood estimate, MLE; neural network, NN; support vector machine, SVM; random forest, RF. 


\subsection{Distribution and Area of KP Community}

According to the vegetation community distribution map acquired by the RF method, the spatial distribution of the KP community was fragmented with large spatial heterogeneity and small area (Figure 5). Among the three counties, the distribution of the KP community was mainly located in: the north, east and around the county urban area of Zeku County (around the town of Zequ, Qiakeri and Xipusha), with an area of $445.60 \mathrm{~km}^{2}$ (6.82\% of Zeku County); the northeast and central part of Henan County (east of county urban area, towns of Tuoyema and Duosun, and north of Saierlong), with an area of $176.76 \mathrm{~km}^{2}$ (4.48\% of Henan County); the part of county urban area, towns of Oulaxiuma, Muxihe and Awancang in Maqu County, with an area of $811.70 \mathrm{~km}^{2}(8.59 \%$ of Maqu County). As a whole, the area of KP community reached $1434.07 \mathrm{~km}^{2}$, and accounted for $7.20 \%$ of the study area.

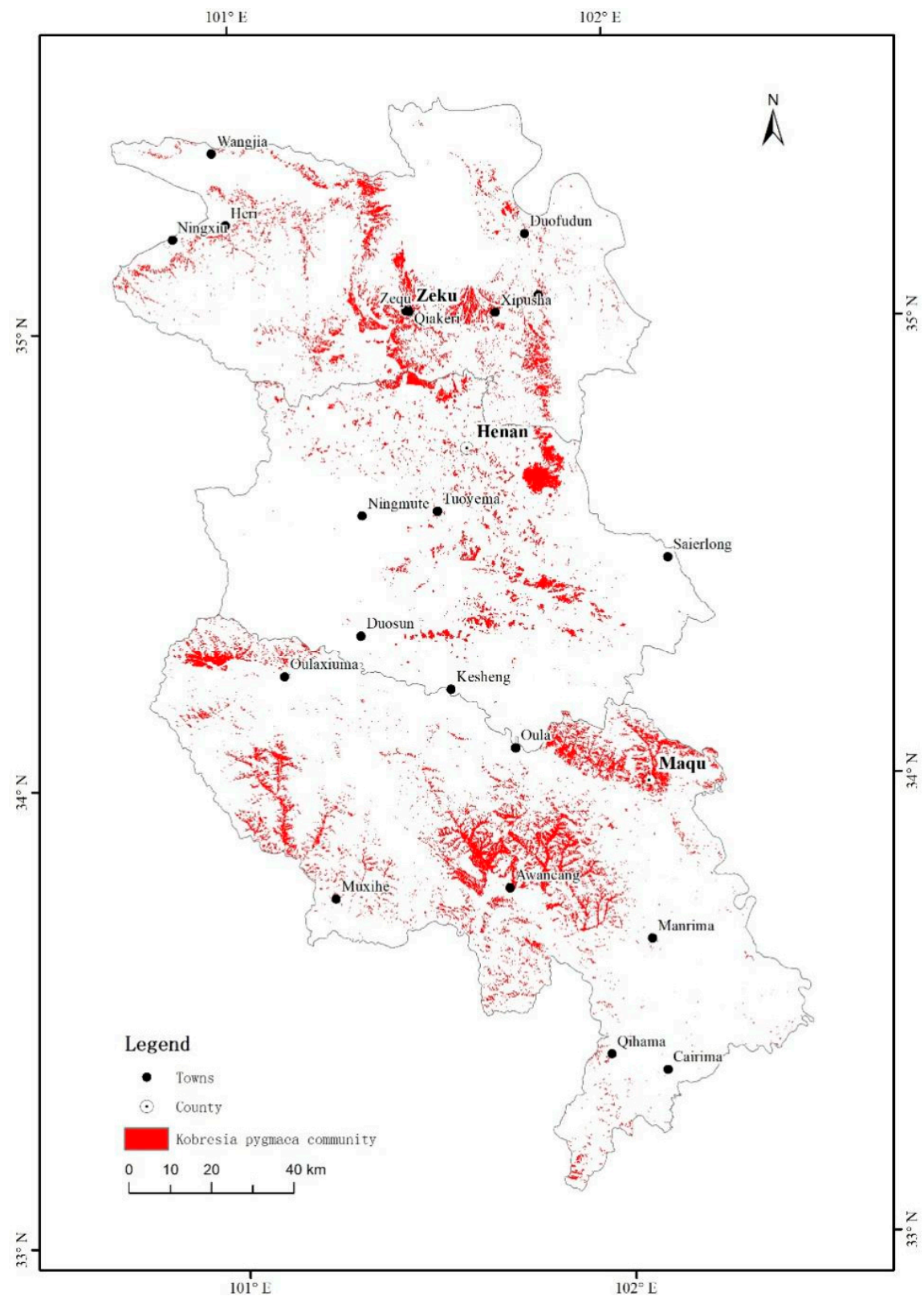

Figure 5. Distribution of Kobresia pygmaea community in Counties of Zeku, Henan and Maqu. 


\section{Discussion}

\subsection{Influence Factors of KP Community in the Qinghai-Tibet Plateau}

Generally, the KP community builds almost closed, non-specific, golf-course like the lawn with a felty root mat. This characteristic mat not only protects soil against intensive trampling by herbivores, but also helps to cope with nutrient limitations enabling medium-term nutrient storage and increasing productivity and competitive ability of roots against leaching and other losses [43-45]. However, with browning (patchwise dieback of lawns), crack, collapse, fragmentation of KP community turf, the water budget [46], carbon cycle $[47,48]$ and soil nutrition $[44,45,49]$ have been significantly changed [10].

Pastoralism may have promoted the dominance of KP community and is a major driver for felty root mat formation [10]. However, the degradation of KP grassland may be caused by both human activities and climate change [9]. The mean annual precipitation in the northern and western parts of the QTP (the elevations ranged from 4400-4800 m) was less than $450 \mathrm{~mm}$, with an increase of inter-annual variability towards the west [2,10]. Grassland suffered from co-limitation of summer rainfall and nutrient shortage [10,50-53]. The types of grassland were diverse, but the species richness was low [10,15]. Hence, the ten distinct plant communities were described in this area [2]. The grassland is dominated by KP community in closed lawns with covers of $98 \%$, and companion species less than $10[10,43]$.

Our study area is located at the eastern edge of the QTP (including three counties), the mean elevation is $3758 \mathrm{~m}$ (Figure 1c) and mean annual precipitation $\geq 450 \mathrm{~mm}$. The alpine meadow in study area consists of four types of vegetation communities, including (a) the Poaceae community (Elymus nutans + Stipa silena + Festuca ovina), (b) the Kobresia humilis community, (c) the Kobresia pygmaea community (KP), and (d) the denuded black soil ecosystem. Those communities consist of more than 40 species, with mosaics of KP community patches and grasses, other sedges and perennial forbs growing as rosettes and cushions $[54,55]$. Overgrazing is the main inducing factor for grassland vegetation community variation $[5,10,56]$, but effect of climate still cannot be eliminated. Although we have mapped the distribution of KP community, the relative contributions from climatic and anthropogenic forces require further investigation. The main effect factor can be distinguished by combining the potential distribution based on the ecological niche model [57] and realistic distribution based on remote sensing, which is very important for alpine meadow protection.

\subsection{Challenges and Prospects for Alpine Meadow Grass Communities Classification}

\subsubsection{Field Observation}

KP community plays a vital role in alpine meadow degradation succession in QTP. However, its spatial distribution is difficult to map: on the one hand, the field observation data is lacking; on the other hand, the distribution of the KP community is under a dynamic variation with different disturbances [5,43]. The massive field observation is the basis of RS classification for grassland community. Traditional grassland vegetation community samples were obtained with the few field investigation, expert knowledge and literature reviews $[11-14,58]$. Field observation is mainly carried out at quadrat, plot and belt transection scales $[15,59,60]$. Due to the complex distribution of grassland vegetation communities, the field investigation is difficult and time-consuming. Meanwhile, the expert knowledge and literature reviews cannot meet the accuracy requirement of classification, because of the subjective bias, the dynamic climate and anthropogenic activities [15,61].

In this study, the field observation was performed by UAV based on FragMAP [14]. The resolution of each aerial photo is $\sim 0.87 \mathrm{~cm}$ and covers $\sim 35 \times 26 \mathrm{~m}$ of ground at the height of $20 \mathrm{~m}$, which is close to the traditional ground observation plot [25,62]. Moreover, the UAV is efficient and easy to operate (about $15 \mathrm{~min}$ to finish each observation site), which provides the possibility for rapid observation in large regions [24]. Most importantly, the waypoints, once established, can be repeatedly used (the error of two flights of the same waypoint is $1-2 \mathrm{~m}$, and two photos on the same waypoint from two different flights 
are almost overlapped). It is suitable to monitor the dynamic variation of grassland communities in a long-term period [25,62].

Limited by the UAV control range and battery life, the size of ROI was only $250 \times 250 \mathrm{~m}$, and the proportion of image raster used for training classification is relatively small. Besides, most of field observation sites were located in the flat area, which was near major traffic roads. Therefore, the spatial distribution of KP community still had some uncertainty in other regions of the study area. Moreover, the vegetation communities were distinguished by manual visual interpretation, and it requires good knowledge of plant taxonomy and time-consuming. Hence, the automatic identification of vegetation community based on aerial photograph and deep learning algorithm requires further exploration.

\subsubsection{Classification Variables}

NDVI, NDWI and SAVI have been commonly used as the classification variables for grassland classification $[20,33,59]$. The vertical variation of grassland vegetation is significantly changed with topographic features in the QTP [63], hence, topographical factor is an important classification basis in alpine vegetation communities classification [64]. Additionally, texture features are also essential variables in object-based classification, which usually reflect local spatial information relating to the change of image tone [16,17]. The common method in texture feature extraction is the grey level co-occurrence matrix (GLCM). The texture metric includes angular second moment, contrast correlation, entropy, homogeneity, difference, average and standard degrees [18]. Incorporating texture feature information usually enhances the recognition of "the same object with different spectrum" or "the different object with same spectrum" [16-18].

Our results showed that, the threshold range of these RS indices for identifying the alpine meadow communities are commonly confused during extraction and identification. According to the descriptive statistical value of those RS indices corresponding to the four alpine meadow grass communities, the threshold range of $\mathrm{KH}$ was close to $\mathrm{KP}$, and that of Poaceae was close to BS among the NDVI, NDWI and SAVI (Figure 6a-c). Although four grass communities could be distinguished in topography and texture metrics, there were relatively few differences and large errors (with little difference in mean values and wide range in variation) (Figure $6 \mathrm{~d}-\mathrm{i}$ ). Therefore, it was difficult to distinguish the alpine meadow grass communities based on single variable and simple combinations [33-35]. RS classification accuracy can be improved by combining the RS, topographic and texture indices (Tables 3 and 4).

Due to large errors in spatial quantification of some variables (such as texture indices), the classification still has some limitations and uncertainties [29]. Hence, we consider using high spatiotemporal resolution images in future research, such as the Sentinel-2A/B satellite images, to reduce the effects of spatial heterogeneity on spectral reflectance and acquire more detailed texture features. Secondly, screening and reconstructing the remote sensing vegetation index: combining existing vegetation index, screening out indices that are more suitable for alpine meadow vegetation community classification.

\subsubsection{Classification Method}

Limited by the low temporal-spatial resolution, few spectrum band of RS images and field observations, most of natural grassland classification were applied in land use types (such as non-grassland, grassland, woodland, etc.) [33], different biophysics characteristics (for example, grassland with high, medium and low coverage) [34] and types with different climatic zones (e.g., groups and types of grassland) [35]. The most frequently used classification methods are visual interpretation, maximum likelihood classifiers, $\mathrm{k}$-nearest neighbor and decision tree classification, and so on [65-67]. With the development of classification methods, the machine learning algorithm has obvious advantages in RS image classification [28,29]. However, the previous grassland classifications have been done at the vegetation type level, and few at the community level $[8,9]$. 


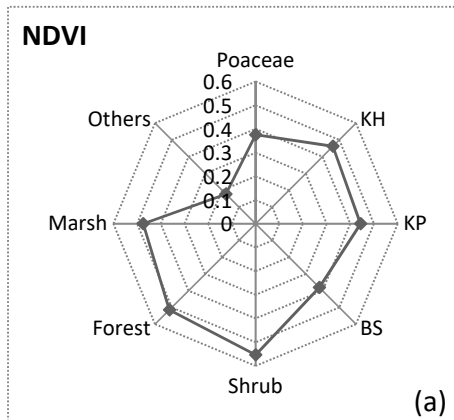

NDWI

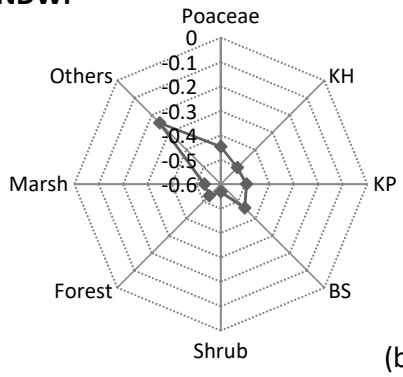

(b)

Slope

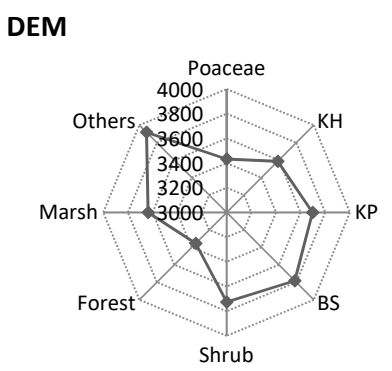

(d)

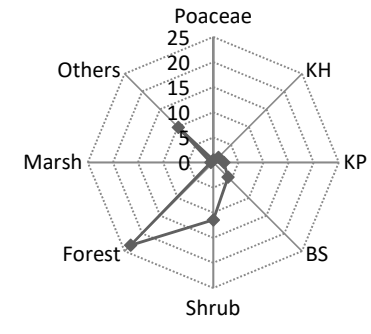

(e)
SAVI

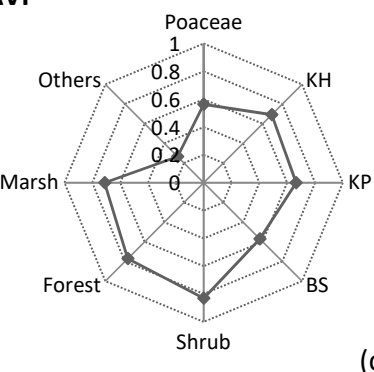

(c)

Asp

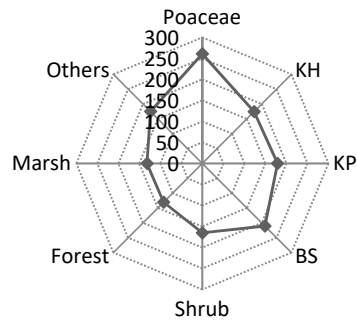

(f)

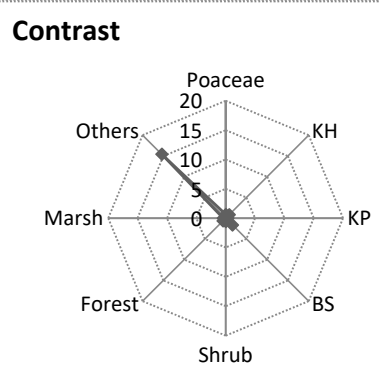

(g)
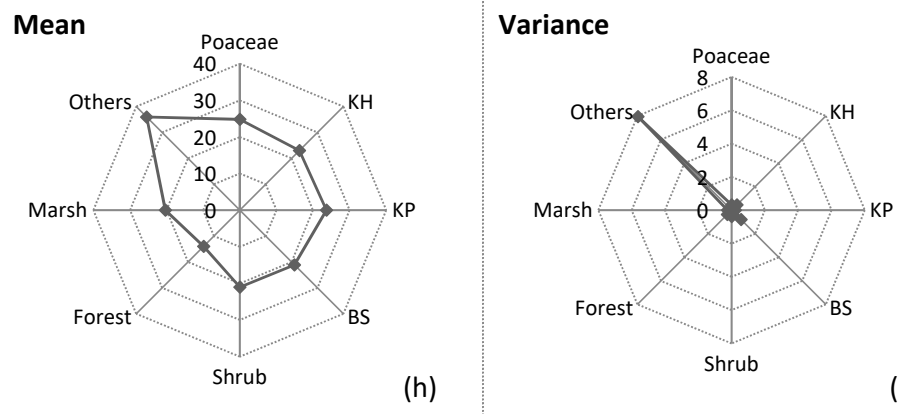

Figure 6. Characteristics of RS indices (a-c), topography (d-f) and texture metrics (g-i) in eight types of land covers: Poaceae, KH, KP and BS represent Elymus nutans + Stipa silena + Festuca ovina, Kobresia humilis, Kobresia pygmaea and black soil type, respectively.

Referenced with previously classification methods [20,58,68,69], the ANN, AVM and RF were used to distinguish the alpine meadow grass communities based on RS, texture and topographic indices in the QTP. Our results demonstrated that the RF algorithm had higher overall accuracy than other algorithms by using the same training samples (with $74.06 \%$ to $83.92 \%$ ). Compared with other methods, RF is a data-driven algorithm. With the increase of input dataset, classification accuracy is improved correspondingly [66,70,71]. The RF algorithm can estimate complex nonlinear relationship and all the quantitative and qualitative information distributed within the models better; thus, these models are robust and fault-tolerant $[69,70]$. Moreover, the input classification indices can be acquired by different multi-spectral remote sensing images, and it helps to integrate multi-source remote sensing data $[66,70,71]$. However, it is difficult to train the RF model effectively with a small sample dataset. RF algorithm composes a large sample decision tree, and classification is performed based on the voting results of each decision tree, thus, has a strong tolerance for data error $[40,41]$. Constructing decision trees consumes more time while performing random forest classification [70]. 


\section{Conclusions}

Based on the band spectral, vegetation indices, texture feature of GaoFen 1/6 wide field view images, topographic indices and UAV field observation, this study examined four classification methods and evaluated their accuracy. Our results showed that the characteristics of RS indices in alpine meadow vegetation communities were very similar, and it was difficult to distinguish the alpine meadow grass communities based on single variable or simple combinations. The KP community could be distinguished through the RF method based on combination of RS, texture and topographic indices. The spatial distribution of KP community was fragmented with large spatial heterogeneity and small area in three counties. The area was $1434.07 \mathrm{~km}^{2}$, which accounted for $7.20 \%$ of the whole study area. Our study demonstrated it was feasible to map at the community level using the satellite remote sensing, UAV surveying and machine learning methods. In future work, more detailed texture features derived from the high spatiotemporal resolution images are required to improve the grassland vegetation community classification.

Supplementary Materials: The following are available online at https://www.mdpi.com/article/10 $.3390 / \mathrm{rs} 13132483$ /s1. Figure S1: Aerial photographs of alpine meadow vegetation communities. a, b, $\mathrm{c}$ and $\mathrm{d}$ were photographs taken at the height of $2 \mathrm{~m}$. e, f, $\mathrm{g}$ and $\mathrm{h}$ were photographs taken at a height of 0.5 m; Poaceae, KH, KP and BS represent communities of Elymus nutans + Stipa silena + Festuca ovina, Kobresia humilis, Kobresia pygmaea and black soil type, respectively. Figure S2: Statistical analysis results of band1 to band8 of GF1/GF6 images; Poaceae, KH, KP and BS represent Elymus nutans + Stipa silena + Festuca ovina, Kobresia humilis, Kobresia pygmaea and black soil type, respectively. Figure S3: Statistical analysis results of texture indices of GF1/GF6 images; Poaceae, $\mathrm{KH}, \mathrm{KP}$ and BS represent Elymus nutans + Stipa silena + Festuca ovina, Kobresia humilis, Kobresia pygmaea and black soil type, respectively. Figure S4: Statistical analysis results of vegetation and topography indices of GF1/GF6 images; Poaceae, KH, KP and BS represent Elymus nutans + Stipa silena + Festuca ovina, Kobresia humilis, Kobresia pygmaea and black soil type, respectively.

Author Contributions: All authors contributed significantly to this manuscript. B.M. and S.Y. designed this study; Z.Y., B.M., H.Y., Y.Q., Y.S., J.Z., J.C., Z.W., W.Z., M.L. and Y.L. were responsible for the field observation, data processing, analysis, and writing of the paper. All authors have read and agreed to the published version of the manuscript.

Funding: This research was funded by the National Key R\&D Program of China (2017YFA0604801), the National Nature Science Foundation of China (42071056, 31901393, 41861016). The APC was funded by National Key R\&D Program of China (2017YFA0604801).

Institutional Review Board Statement: Not applicable.

Informed Consent Statement: Not applicable.

Data Availability Statement: GF1 and GF6 WFV imager images were downloaded from the China Centre for Resources Satellite Data and Application (http:/ / www.cresda.com/EN/, accessed on 5 May 2020); The DEM data were 90 m shuttle radar topography mission (SRTM) images (version V004) (http:/ / srtm.csi.cgiar.org/, accessed on 5 May 2020).

Acknowledgments: The authors thanks the Three-River-Source National Park Administration for their help in field sampling. We also appreciate the editor's and reviewers' constructive suggestions to greatly improve the paper.

Conflicts of Interest: the authors declare no conflict of interest.

\section{References}

1. The Editorial Committee of Vegetation Map of China, Chinese Academy of Sciences. Vegetation of China and Its Geographic Pattern: Illustration of the Vegetation Map of the People's Republic of China (1:1,000,000); Geological Publishing House: Beijing, China, 2007. (In Chinese)

2. Miehe, G.; Bach, K.; Miehe, S.; Kluge, J.; Yang, Y.; Duo, L.; Co, S.; Wesche, K. Alpine steppe plant communities of the Tibetan highlands. Appl. Veg. Sci. 2011, 14, 547-560. [CrossRef]

3. Wang, P.; Lassoie, J.; Morreale, S.; Dong, S. A critical review of socioeconomic and natural factors in ecological degradation on the Qinghai-Tibetan Plateau, China. Rangeland J. 2015, 37, 1-9. [CrossRef] 
4. Liu, S.; Zamanian, K.; Schleuss, P.; Zarebanadkouki, M.; Kuzyakov, Y. Degradation of Tibetan grasslands: Consequences for carbon and nutrient cycles. Agric. Ecosyst. Environ. 2018, 252, 93-104. [CrossRef]

5. Cao, G.M.; Long, R.J. System Stability and its Self-maintaining Mechanism by Grazing in Alpine Kobresia Meadow. Chin. J. Agrometeorol. 2009, 30, 553-559.

6. Lin, L. Response and Adaptation of Plant-Soil System of Alpine Meadows in Different Successional Stages to Grazing Intensity. Ph.D. Thesis, Gansu Agricultural University, Lanzhou, China, 2017.

7. Li, X.; Gao, J.; Brierley, G.; Qiao, Y.; Zhang, J.; Yang, Y. Rangeland degradation on the Qinghai-Tibet Plateau: Implications for rehabilitation. Land Degrad. Dev. 2013, 24, 72-80. [CrossRef]

8. Ma, Z.; Liu, H.; Mi, Z.; Zhang, Z.; Wang, Y.; Xu, W.; Jiang, L.; He, J.S. Climate warming reduces the temporal stability of plant community biomass production. Nat. Commun. 2017, 8, 15378. [CrossRef] [PubMed]

9. Li, L.; Zhang, Y.; Liu, L.; Wu, J.; Li, S.; Zhang, H.; Zhang, B.; Ding, M.; Wang, Z.; Paudel, B. Current challenges in distinguishing climatic and anthropogenic contributions to alpine grassland variation on the Tibetan Plateau. Ecol. Evol. 2018, 8, 5949. [CrossRef] [PubMed]

10. Miehe, G.; Schleuss, P.; Seeber, E.; Babel, W.; Biermann, T.; Braendle, M.; Chen, F.; Coners, H.; Foken, T.; Gerkenj, T.; et al. The Kobresia pygmaea ecosystem of the Tibetan highlands-origin, functioning and degradation of the world's largest pastoral alpine ecosystem Kobresia pastures of Tibet. Sci. Total Environ. 2019, 648, 754-771. [CrossRef]

11. Beard, J.S. The vegetation survey of Western Australia. Vegetatio 1975, 30, 179-187. [CrossRef]

12. Cawsey, E.; Austin, M.; Baker, B.L. Regional vegetation mapping in Australia: A case study in the practical use of statistical modelling. Biodivers. Conserv. 2002, 11, 2239-2274. [CrossRef]

13. Naidoo, R.; Hill, K. Emergence of indigenous vegetation classifications through integration of traditional ecological knowledge and remote sensing analyses. Environ. Manag. 2006, 38, 377-387. [CrossRef]

14. Bartha, S. A grid-based, satellite-image supported, multi-attributed vegetation mapping method (MTA). Folia Geobot. 2007, 42, 225-247.

15. Su, Y.; Guo, Q.; Hu, T.; Guan, H.; Jin, S.; An, S.; Chen, X.; Guo, K.; Hao, Z.; Hu, Y.; et al. An Updated Vegetation Map of China (1:1000000). Sci. Bull. 2020, 65, 1125-1136. [CrossRef]

16. Palm, C. Color texture classification by integrative co-occurrence matrices. Pattern Recognit. 2004, 37, 965-976. [CrossRef]

17. Pietikäinen, M.; Mäenpää, T.; Viertola, J. Color texture classification with color histograms and local binary patterns. Presented at the Workshop on Texture Analysis in Machine Vision, Oulu, Finland, 14-15 June 1999; pp. 14-15.

18. Arif, M.S.M.; Gülch, E.; Tuhtan, J.A.; Thumser, P.; Haas, C. An investigation of image processing techniques for substrate classification based on dominant grain size using rgb images from uav. Int. J. Remote Sens. 2017, 38, 2639-2661. [CrossRef]

19. Wang, L.; Yang, R.; Tian, Q.; Yang, Y.; Zhou, Y.; Sun, Y.; Mi, X. Comparative Analysis of GF-1 WFV, ZY-3 MUX, and HJ-1 CCD Sensor Data for Grassland Monitoring Applications. Remote Sens. 2015, 7, 2089-2108. [CrossRef]

20. Chen, Q.; Yu, R.; Hao, Y.; Wu, L.; Zhang, W.; Zhang, Q.; Bu, X. A new method for mapping aquatic vegetation especially underwater vegetation in lake ulansuhai using GF-1 satellite data. Remote Sens. 2018, 10, 1279. [CrossRef]

21. Yang, Y.; Zhan, Y.; Tian, Q.; Gu, X.; Yu, T.; Wang, L. Crop classification based on GF-1/WFV NDVI time series. Trans. Chin. Soc. Agric. Eng. 2015, 31, 155-161.

22. Yi, S.; Chen, J.; Qin, Y.; Xu, G.W. The burying and grazing effects of plateau pika on alpine grassland are small: A pilot study in a semiarid basin on the Qinghai-Tibet Plateau. Biogeosciences 2016, 13, 6273. [CrossRef]

23. Ge, J.; Meng, B.P.; Liang, T.G.; Feng, Q.S.; Gao, J.L.; Yang, S.X.; Huang, X.D.; Xie, H.J. Modeling alpine grassland cover based on MODIS data and support vector machine regression in the headwater region of the Huanghe River, China. Remote Sens. Environ. 2018, 218, 162-173. [CrossRef]

24. Meng, B.P.; Gao, J.; Liang, T.; Cui, X.; Ge, J.; Yin, J.; Feng, Q.; Xie, H. Modeling of alpine grassland cover based on unmanned aerial vehicle technology and multi-factor methods: A case study in the east of Tibetan Plateau, China. Remote Sens. 2018, 10, 320. [CrossRef]

25. Sun, Y.; Yi, S.H.; Hou, F.J. Unmanned aerial vehicle methods makes species composition monitoring easier in grasslands. Ecol. Indic. 2018, 95, 825-830. [CrossRef]

26. Yi, S. FragMAP: A tool for long-term and cooperative monitoring and analysis of small-scale habitat fragmentation using an unmanned aerial vehicle. Int. J. Remote Sens. 2017, 38, 8-10. [CrossRef]

27. Guo, X.; Yi, S.; Qin, Y.; Chen, J. Habitat environment affects the distribution of plateau pikas:A study based on an unmanned aerial vehicle. Pratacultural Sci. 2017, 34, 1306-1313.

28. Liang, T.; Yang, S.; Feng, Q.; Liu, B.; Zhang, R.; Huang, X.; Xie, H. Multi-factor modeling of above-ground biomass in alpine grassland: A case study in the Three-River Headwaters Region, China. Remote Sens. Environ. 2016, 186, 164-172. [CrossRef]

29. Meng, B.P.; Yi, S.H.; Liang, T.G.; Yin, J.P.; Cui, X.; Ge, J.; Hou, M.J.; Lv, Y.Y. Modeling Alpine Grassland Above Ground Biomass Based on Remote Sensing Data and Machine Learning Algorithm: A Case Study in East of the Tibetan Plateau, China. IEEE J. Sel. Top. Appl. Earth Obs. Remote Sens. 2020, 13, 2986-2995. [CrossRef]

30. Dong, S.W.; Sun, D.F.; Li, H. Crop Decision Tree Classification Extraction Based on MODIS NDVI in Beijing. Adv. Mater. Res. 2014, 955-959, 787-790. [CrossRef]

31. Li, D.; Yang, F.; Wang, X. Study on Ensemble Crop Information Extraction of Remote Sensing Images Based on SVM and BPNN. J. Indian Soc. Remote Sens. 2016, 45, 1-9. [CrossRef] 
32. Hou, M.J.; Ge, J.; Gao, J.L.; Meng, B.P.; Li, Y.C.; Yin, J.P.; Liu, J.; Feng, Q.S.; Liang, T.G. Ecological risk assessment and impact factor analysis of alpine wetland ecosystem based on LUCC and boosted regression tree on the Zoige Plateau, China. Remote Sens. 2020, 12, 368. [CrossRef]

33. Hao, C.; Wu, S. The effects of land-use types and conversions on desertification in Mu Us Sandy Land of China. J. Geogr. Sci. 2006, 16, 57-68. [CrossRef]

34. Wiesmair, M.; Feilhauer, H.; Magiera, A.; Otte, A.; Waldhardt, R. Estimating Vegetation Cover from High-Resolution Satellite Data to Assess Grassland Degradation in the Georgian Caucasus. Mt. Res. Dev. 2016, 36, 56-65. [CrossRef]

35. Feng, Q.; Liang, T.; Huang, X.; Lin, H.; Xie, H.; Ren, J. Characteristics of global potential natural vegetation distribution from 1911 to 2000 based on comprehensive sequential classification system approach. Grassl. Sci. 2013, 59, 87-99. [CrossRef]

36. Xu, K. Maximum Likelihood Estimate. Encycl. Syst. Biol. 2013, 38, 1-4.

37. He, Q. Neural network and its application in IR; Graduate School of Library and Information Science, Urbana-Champaign: Champaign, IL, USA, 2008.

38. Vapnik, V.N. The Nature of Statistical Learning Theory; Springer: New York, NY, USA, 1995.

39. Chang, C.C.; Lin, C.J. LIBSVM: A library for support vector machines. ACM Trans. Intell. Syst. Technol. 2011, 2, 27. [CrossRef]

40. Breiman, L. Bagging predictors. Mach. Learn. 1996, 24, 123-140. [CrossRef]

41. Breiman, L. Random Forests. Mach. Learn. 2001, 45, 5-32. [CrossRef]

42. Van der Linden, S.; Rabe, A.; Held, M.; Jakimow, B.; Leitão, P.J.; Okujeni, A.; Schwieder, M.; Suess, S.; Hostert, P. The EnMAPBox-A Toolbox and Application Programming Interface for EnMAP Data Processing. Remote Sens. 2015, 7, 11249-11266. [CrossRef]

43. Miehe, G.; Miehe, S.; Kaiser, K.; Liu, J.; Zhao, X. Status and dynamics of the Kobresia pygmaea ecosystem on the Tibetan Plateau. Ambio 2008, 37, 272-279. [CrossRef]

44. Schleuss, P.-M.; Heitkamp, F.; Sun, Y.; Miehe, G.; Xu, X.; Kuzyakov, Y. Nitrogen uptake in an alpine Kobresia pasture on the Tibetan Plateau: Localization by $15 \mathrm{~N}$ labeling and implications for a vulnerable ecosystem. Ecosystems 2015, 18, 946-957. [CrossRef]

45. Sun, Y.; Schleuss, P.M.; Pausch, J.; Xu, X.; Kuzyakov, Y. Nitrogen pools and cycles in Tibetan Kobresia pastures depending on grazing. Biol. Fertil. Soils 2018, 54, 569-581. [CrossRef]

46. Babel, W.; Biermann, T.; Coners, H.; Falge, E.; Seeber, E.; Ingrisch, J.; Schleuss, P.; Gerken, T.; Leonacher, J.; Leipold, T. Pasture degradation modifies the water and carbon cycles of the Tibetan highlands. Biogeosciences 2014, 11, 6633-6656. [CrossRef]

47. Wu, Y.; Tan, H.; Deng, Y.; Wu, J.; Xu, X.L.; Wang, Y.; Tang, Y.; Higashi, T.; Cui, X. Partitioning pattern of carbon flux in a Kobresia grassland on the Qinghai-Tibetan Plateau revealed by field 13C pulse-labeling. Glob. Chang. Biol. 2010, 16, 2322-2333. [CrossRef]

48. Hafner, S.; Unteregelsbacher, S.; Seeber, E.; Lena, B.; Xu, X.; Guggenberger, G.; Miehe, G.; Kuzyakov, Y. Effect of grazing on carbon stocks and assimilate partitioning in a Tibetan montane pasture revealed by 13CO2 pulse labeling. Glob. Chang. Biol. 2012, 18, 528-538. [CrossRef]

49. Ingrisch, J.; Biermann, T.; Seeber, E.; Leipold, T.; Li, M.; Ma, Y.; Xu, X.; Guggenerger, G.; Foken, T. Carbon pools and fluxes in a Tibetan alpine Kobresia pygmaea pasture partitioned by coupled eddy-covariance measurements and ${ }^{13} \mathrm{CO}_{2}$ pulse labeling. Sci. Total Environ. 2015, 505, 1213-1224. [CrossRef]

50. Li, J.M.; Ehlers, T.A.; Werner, M.; Mutz, S.G.; Steger, C.; Paeth, H. Late Quaternary climate, precipitation ${ }^{18} \mathrm{O}$, and Indian monsoon variations over the Tibetan Plateau. Earth Planet. Sci. Lett. 2016, 457, 412-422. [CrossRef]

51. Li, R.; Luo, T.; Molg, T.; Zhao, J.; Li, X.; Cui, X.; Du, M.; Tang, Y. Leaf unfolding of Tibetan alpine meadows captures the arrival of monsoon rainfall. Sci. Rep. 2016, 6, 20985. [CrossRef] [PubMed]

52. Miehe, G.; Miehe, S. Environmental changes in the pastures of Xizang. Marbg. Geogr. Schr. 2000, 135, $282-311$.

53. Lehnert, L.W.; Wesche, K.; Trachte, K.; Reudenbach, C.; Bendix, J. Climate variability rather than overstocking causes recent large scale cover changes of Tibetan pastures. Sci. Rep. 2016, 6, 24367. [CrossRef]

54. Wang, Y.; Heberling, G.; Görzen, E.; Miehe, G.; Seeber, E.; Wesche, K. Combined effects of livestock grazing and abiotic environment on vegetation and soils of grasslands across Tibet. Appl. Veg. Sci. 2017, 20, 327-339. [CrossRef]

55. Niu, Y.; Zhu, H.; Yang, S.; Ma, S.; Zhou, J.; Chu, B.; Hua, R.; Hua, L. Overgrazing leads to soil cracking that later triggers the severe degradation of alpine meadows on the Tibetan Plateau. Land Degrad. Dev. 2019, 30, 1243-1257. [CrossRef]

56. Zhou, H.; Zhao, X.; Tang, Y.; Gu, S.; Zhou, L. Alpine grassland degradation and its control in the source region of the Yangtze and Yellow Rivers, China. Grassl. Sci. 2005, 51, 191-203. [CrossRef]

57. Feng, X.; Park, D.; Walker, C.; Peterson, A.; Merow, C.; Papes, M. A checklist for maximizing reproducibility of ecologicla niche model. Nat. Ecol. Evol. 2019, 3, 1382-1395. [CrossRef]

58. Pedrotti, F. Plant and Vegetation Mapping; Springer: Berlin, Germany, 2013.

59. Wen, Q.; Zhang, Z.; Liu, S.; Wang, X.; Wang, C. Classification of Grassland Types by MODIS Time-Series Images in Tibet, China. IEEE J. Sel. Top. Appl. Earth Obs. Remote Sens. 2010, 3, 404-409. [CrossRef]

60. Yu, K.F.; Lehmkuhl, F.; Falk, D. Quantifying land degradation in the Zoige Basin, NE Tibetan Plateau using satellite remote sensing data. J. Mt. Sci. 2017, 14, 77-93. [CrossRef]

61. Guo, D.; Song, X.; Hu, R.; Cai, S.; Zhu, X.; Hao, Y. Grassland type-dependent spatiotemporal characteristics of productivity in Inner Mongolia and its response to climate factors. Sci. Total. Environ. 2021, 775, 145644. [CrossRef] 
62. Zhang, J.; Liu, D.; Meng, B.; Chen, J.; Wang, X.; Jiang, H.; Yu, Y.; Yi, S. Using UAVs to assess the relationship between alpine meadow bare patches and disturbance by pikas in the source region of Yellow River on the Qinghai-Tibetan Plateau. Glob. Ecol. Conserv. 2021, 26, e01517. [CrossRef]

63. Ma, W.W. Study on Methods for Grassland Classification and Quality Estimation by Remote Sensing: A Case Study in the Region around Qinghai Lake; Chinese Academy of Science: Beijing, China, 2015.

64. Bolstad, P.V.; Lillesand, T.M. Improved Classification of Forest Vegetation in Northern Wisconsin Through a Rule-Based Combination of Soils, Terrain, and Landsat Thematic Mapper Data. For. Sci. 1992, 1, 5-20.

65. Settle, J.J.; Briggs, S.A. Fast maximum-likelihood class-ification of remotely sensed imagery. Int. J. Remote Sens. 1987, 8, 723-734. [CrossRef]

66. Zhu, H.W.; Basir, O. An adaptive fuzzy evidential nearest neighbor formulation for classifying remote sensing images. IEEE Trans. Geosci. Remote Sens. 2005, 43, 1874-1889.

67. Navin, M.S.; Agilandeeswari, L. Comprehensive review on land use/land cover change classification in remote sensing. J. Spectr. Imaging. 2020, 9, a8. [CrossRef]

68. Jiang, L.C.; Wang, Y. Mapping zoige alpine wetland using random forest classification and landsat 5 TM data. Stud. Surv. Mapp. Sci. (SSMS) 2016, 4, 24-27.

69. Qiao, Y.; Chen, T.; Qiang, W.; Feng, T. Method of grassland information extraction based on multi-level segmentation and cart model. Int. Arch. Photogramm. Remote Sens. Spatial Inf. Sci. 2018, XLII-3, 1415-1420. [CrossRef]

70. He, T.; Wang, S. Multi-spectral remote sensing land-cover classification based on deep learning methods. J. Supercomput. 2020, 77, 2829-2843. [CrossRef]

71. Yuan, H.; Yang, G.; Li, C.; Wang, Y.; Liu, J.; Yu, H.; Feng, H.; Xu, B.; Zhao, X.; Yang, X. Retrieving Soybean Leaf Area Index from Unmanned Aerial Vehicle Hyperspectral Remote Sensing: Analysis of RF, ANN, and SVM Regression Models. Remote Sens. 2017, 9, 309. [CrossRef] 